Article

\title{
Evaluation of Anti-Wear Properties of Metalworking Fluids Enhanced with Halloysite Nanotubes
}

\author{
Laura Peña-Parás 1,* (D), José Antonio Sánchez-Fernández ${ }^{2}$, Carlos Rafael Martínez ${ }^{1}$, \\ José Abraham Ontiveros ${ }^{1}$, Karla Itzel Saldívar ${ }^{1}$, Luis Manuel Urbina ${ }^{1}$, Moisés Jair Arias ${ }^{1}$, \\ Patricio García-Pineda ${ }^{1}$ and Brenda Castaños ${ }^{1}$ \\ 1 Departamento de Ingeniería, Universidad de Monterrey, \\ 66238 San Pedro Garza García, Nuevo León, Mexico; carlos.martinezc@udem.edu (C.R.M.); \\ jose.ontiverosg@udem.edu (J.A.O.); karla.saldivar@udem.edu (K.I.S.); luis.urbina@udem.edu (L.M.U.); \\ moises.arias@udem.edu (M.J.A.); patricio.garcia@udem.edu (P.G.-P.); brenda.castanos@udem.edu (B.C.) \\ 2 Escuela de Ingeniería y Ciencias, Tecnológico de Monterrey, Campus Monterrey, Eugenio Garza Sada 2501, \\ Col. Tecnológico, 64849 Monterrey, Nuevo León, Mexico; asanfer@itesm.mx \\ * Correspondence: laura.pena@udem.edu; Tel.: +52-8182151000 (ext. 1894)
}

Received: 22 August 2017; Accepted: 25 September 2017; Published: 3 October 2017

Featured Application: nanoparticle additives for improving tribological properties of metalworking cutting fluids, enhancing tool life and surface finish in machining processes.

\begin{abstract}
The study of nanoparticles as additives for metalworking fluids (MWFs) with applications in the metal removal processes, or machining, has received increasing attention due to the possible enhancements on tribological properties. In this study, low-cost and environmentally friendly nanoparticle additives of halloysite clay nanotubes (HNTs) were dispersed in metalworking fluids utilized for milling processes. Concentrations of $0.01,0.05,0.10 \mathrm{wt}$. \% were incorporated into a mineral oil (MO) and a semi-synthetic fluid (SF) by ultrasonication. The anti-wear properties of metalworking nanofluids were characterized with a T-05 block-on-ring tribotester at a contact pressure of $0.5 \mathrm{GPa}$. Surface roughness of worn block materials was obtained with an optical 3D surface measurement system. Results showed that at a concentration of $0.10 \mathrm{wt}$. \% HNTs block mass loss was lowered by $24 \%$ for the MO + HNTs nanofluids. For the SF + HNTs, a reduction of $63 \%$ and $32 \%$ in wear mass loss and coefficient of friction (COF), respectively, were found at the same concentration. The tribological enhancing mechanism for the applied contact pressure was proposed to be due to a reduction of the area of contact and nanoparticle sliding between surfaces with no HNT deposition, evidenced by energy dispersive spectrometry (EDS). Furthermore, surface roughness studies of worn blocks showed smoother surfaces with lower groove density with the addition of nanoparticle additives. The results of this study demonstrate that HNTs can improve the lubricity of metalworking cutting fluids used for machining processes, enhancing tool life and providing better surface finish of products.
\end{abstract}

Keywords: nanofluids; metalworking fluids; halloysite nanotubes; wear; coefficient of friction; surface roughness

\section{Introduction}

Metalworking fluids (MWFs) are used in metal removal processes such as cutting, milling, and grinding to reduce friction between the tool and the workpiece, increase tool life by reducing wear, and improve surface finish [1-4]. MWFs with nanoparticle additives have been widely investigated for the purpose of reducing the mechanical friction and wear between components obtaining very promising results [5-14]. For example, the wear scar diameters (WSDs) of a synthetic 
fluid and base oil for machining applications were lowered by $10 \%$ and $86 \%$, respectively, with 0.01 wt. \% CuO nanoparticles [10]. Similarly, Mosleh et al. [15] dispersed $\mathrm{MoS}_{2}, \mathrm{WS}_{2}$, and hexagonal boron nitride (hBN) nanoparticles in MWFs obtaining wear reductions of up to $66 \%$. This was attributed to nanoparticles filling surface valleys and the shearing of trapped nanoparticles at the interface of contacting surfaces. Another study by Mosleh et al. [12] found that nanoparticles also deagglomerate metallic transfer films further reducing friction and wear. Zhang et al. [16] dispersed $\mathrm{CaCO}_{3}$ nanoparticles in a poly-alpha-olefin (PAO) base oil improving load-carrying capacity, and reducing friction and wear. Significant friction reductions in boundary and mixed lubrication regimes were obtained by Kalin et al. [17] through the formation of a protective film by dispersing $\mathrm{MoS}_{2}$ nanotubes into PAO. Moreover, Wu et al. [5] achieved reductions in friction and wear by $\mathrm{CuO}$, $\mathrm{TiO}_{2}$, and nano-diamond nanoparticles due to a rolling effect provided by their spherical shape.

The addition of nanoparticles to MWFs has also demonstrated improvements in tool life and surface finish of products. Exfoliated graphene nanoparticles added to a vegetable oil reduced edge chipping of cutting tool edges in ball milling experiments [18]. A cutting fluid with dispersed $\mathrm{CuO}$ nanoparticles developed by Vázquez et al. [11] was employed in a Computer Numerical Control (CNC) gear generator obtaining an improvement on the surface finish of workpieces of $\sim 52 \%$. Nanoparticles of $\mathrm{SiO}_{2}$ blended into a mineral oil investigated for plain bearings by Sia et al. $[19,20]$ reduced friction temperatures by acting as rolling and sliding particles between surfaces. Furthermore, a nanolubricant containing $\mathrm{MoS}_{2}$ nanoparticles for end-milling of AL6061-T6 developed by Rahmati et al. [21] improved the quality of the machined surfaces by the rolling, mending, and polishing tribological mechanisms provided by $\mathrm{MoS}_{2}$ in the tool-workpiece interface.

Halloysite nanotubes (HNTs), with a molecular formula of $\mathrm{Al}_{2} \mathrm{Si}_{2} \mathrm{O}_{5}(\mathrm{OH})_{4} \cdot \mathrm{nH}_{2} \mathrm{O}$, are hollow clay multiwalled tubular nanoparticles with lengths of 50-5000 nm, diameters of 20-200 nm, and inner lumen of $10-70 \mathrm{~nm}$ that naturally form in the Earth [22-24]; however, their dimensions may vary depending on the deposit [25]. These nanoparticles have negatively charged $\mathrm{SiO}_{2}$ groups on the outside of the layers and positively charged $\mathrm{Al}(\mathrm{OH})_{3}$ on the inner lumen [26-28]. HNTs are non-toxic even at high concentrations, and are much less expensive compared to other tubular-like nanoparticles such as carbon nanotubes (CNTs) [22]. Due to these characteristics they have been studied for diverse applications, such as for preparing colloids with biopolymers providing tunable properties [29], for drug transport and delivery [28], as nanocontainers of additives for paper preservation [30], for obtaining inorganic reverse micelles for the entrapment of antibacterial agents [31], and for capturing hydrocarbon and aromatic oils [32].

Recently, our group demonstrated that HNTs dispersed in metal-forming lubricants tested under extreme pressure conditions are able to increase the load-carrying capacity, scuffing load, and seizure load (load for lubricant film breakdown) under contacts pressures of 3.5-3.9 GPa [33]. At this high contact pressure the tribological enhancing mechanism of HNTs was due to a possible exfoliation of their outer sheets and deposition on the surfaces.

In this work, two MWFs commonly used in the metal-mechanic industry, a semi-synthetic fluid (SF) and a mineral oil (MO), were reinforced with varying concentrations of HNTs and tested under a contact pressure of $0.5 \mathrm{GPa}$ (lower than our previous work). The tribological properties of coefficient of friction (COF) and wear mass loss of nanofluids were determined with a block-on-ring test performed at room temperature. Surface roughness of tested materials was characterized after the test to study the influence of these nanoparticles on the surface finish of blocks. The proposed tribological enhancing mechanism of this study was determined by energy dispersive spectrometry (EDS).

\section{Materials and Methods}

\subsection{Materials}

Nanofluids were prepared by adding HNTs (purchased from Sigma-Aldrich, St. Louis, MO, USA) in concentrations of $0.01,0.05$, and $0.10 \mathrm{wt}$. \% within a MO and a SF. These concentrations 
were selected based on a previous study by our group [33]. Figure 1a shows a micrograph with the morphology on HNTs obtained by scanning electron microscopy (SEM). Dimension measurements of HNTs obtained by SEM are observed in Figure 1b. Elemental analysis of HNTs in Figure 1c shows Al, $\mathrm{Si}$, and $\mathrm{O}$ in concentrations of $26 \%, 26 \%$, and $43 \%$, respectively. Also, Table 1 presents the properties of nanoparticles and MWFs. Nanoparticles were dispersed in both MWFs using an Ultra Turraz T10 homogenizer for $5 \mathrm{~min}$ at room temperature $\left(25^{\circ} \mathrm{C}\right)$, followed by $5 \mathrm{~min}$ of ultrasonication with a Cole-Parmer 750-watt ultrasonic homogenizer.

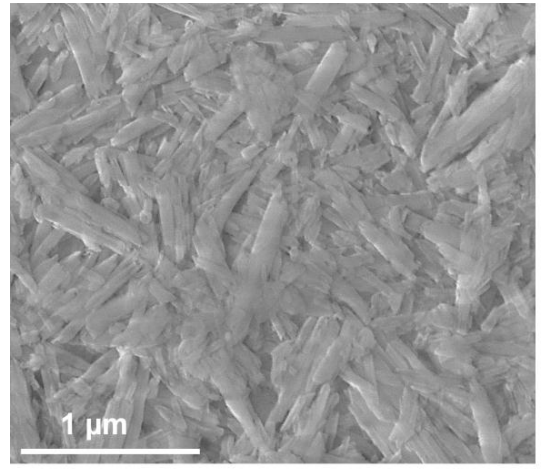

(a)

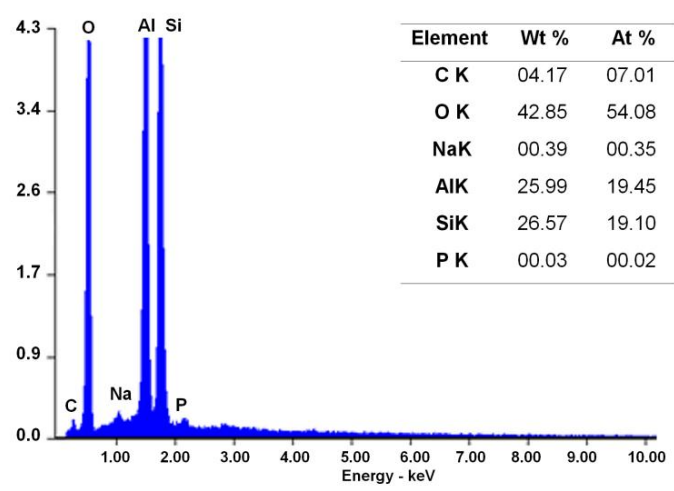

(c)

\section{1}

4.08

0.35

9.45

9.10

0.02

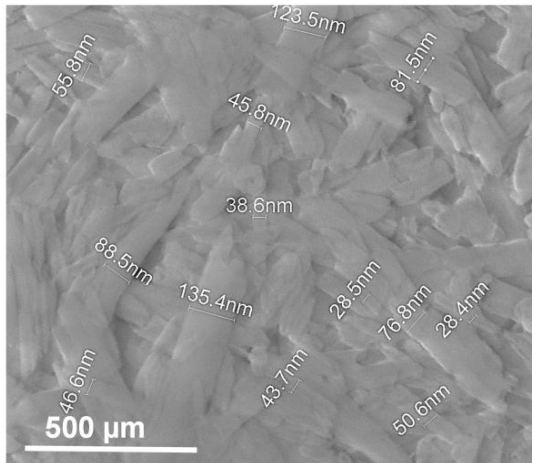

(b)

Figure 1. (a) Scanning electron micrograph of halloysite nanotubes (HNTs); (b) Micrograph of HNTs at higher magnification indicating nanoparticle dimensions; (c) elemental analysis of HNTs showing high concentrations of $\mathrm{Al}, \mathrm{Si}$, and $\mathrm{O}$.

Table 1. Material properties.

\begin{tabular}{ccc}
\hline Materials & Properties \\
\hline Metalworking fluids & Density $\left(\mathbf{1 5}{ }^{\circ} \mathbf{C}\right)$ & Viscosity $\left(\mathbf{4 0}{ }^{\circ} \mathbf{C}\right)$ \\
\hline Semi-synthetic fluid (SF) & $0.970 \mathrm{~g} / \mathrm{cm}^{3}$ & $75.0 \mathrm{~mm}^{2} / \mathrm{s}$ \\
\hline Mineral oil (MO) & $0.871 \mathrm{~g} / \mathrm{cm}^{3}$ & $33.2 \mathrm{~mm}^{2} / \mathrm{s}$ \\
\hline Nanoparticle & & \\
\hline Halloysite clay nanotubes (HNTs) & Morphology: tubular; diameter: $28.5-135 \mathrm{~nm} \times$ length: $1-3 \mu \mathrm{m}$ \\
\hline Test blocks & & \\
\hline AISI 1018 & Dimensions: $6.35 \times 10 \times 15.75 \mathrm{~mm}, 71 \mathrm{HRB}, R_{a}=0.45 \mu \mathrm{m}$ \\
\hline Test rings & Chemical composition: $0.14-0.20 \%$ C, $0.60-0.90 \%$ Mn, $<0.04 \% \mathrm{P}, 0.05 \%$, Fe Balance \\
\hline AISI D2 & & \\
\hline & Diameter: $35 \mathrm{~mm}, 58 \mathrm{HRC}, R_{a}=0.65 \mu \mathrm{m}$ \\
& & \\
\hline
\end{tabular}


Figure 2 shows the hydrodynamic diameter size distribution of HNTs over time for MO and SF nanofluids, where measurements were taken after following the dispersion method. These tests were performed with a Malvern Zetasizer Nano ZS using dynamic light scattering after 3, 6, and 9 min. In Figure 2a the HNTs hydrodynamic diameter size distribution increases rapidly with time for MO nanofluids, suggesting lower stability in this fluid, likely due to its lower viscosity $\left(33.2 \mathrm{~mm}^{2} / \mathrm{s}\right)$ compared to SF $\left(75.0 \mathrm{~mm}^{2} / \mathrm{s}\right)$. For SF nanofluids the size distribution remains stable with very similar curves (Figure 2b). Figure 2c shows a plot of the average HNTs hydrodynamic diameter size over time, indicating the lower stability in MO.

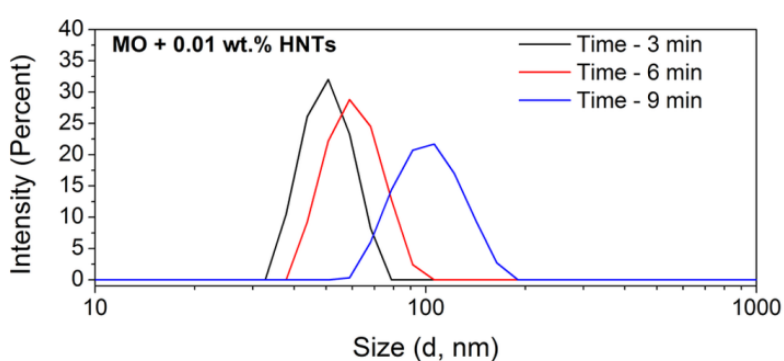

(a)

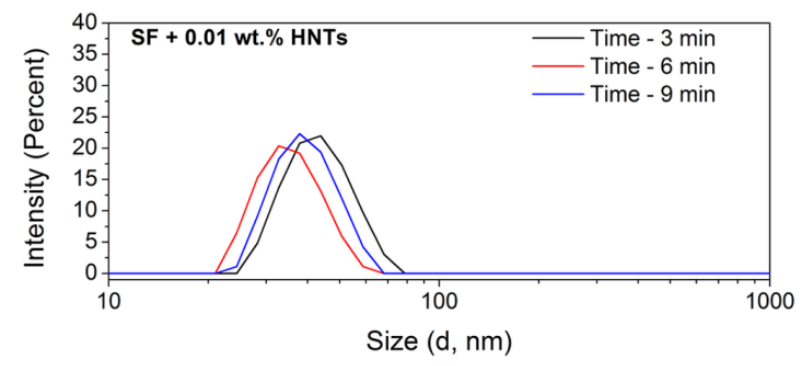

(b)

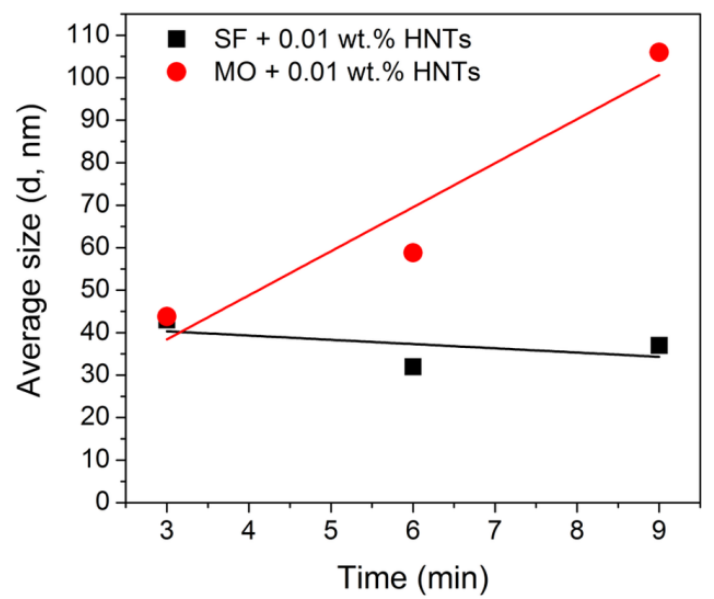

(c)

Figure 2. (a) Hydrodynamic size distribution of HNTs over time for $\mathrm{MO}+0.01$ wt. \% HNT; (b) Hydrodynamic size distribution of HNTs over time for SF + $0.01 \mathrm{wt}$. \% HNTs; (c) Average HNTs hydrodynamic diameter over time comparison for MO + 0.01 wt. \% HNTs and SF + 0.01 wt. \% HNTs. Lower stability is found for MO nanofluids.

\subsection{Tribological Tests}

Tribological characterization of nanofluids was performed with a T-05 block-on-ring tribotester shown in Figure 3a, according to ASTM G77. The schematic of the block-on-ring configuration used for this study indicating the direction of the applied load is shown in Figure 3b. Figure 3c shows the dimensions of test block and ring samples.

In this test a normal load is applied to the system (Figure 3b), where the test block is locked into position and the ring rotates with a selected speed and load. Approximately $50 \mathrm{~mL}$ of nanofluids are placed in the lubricant container so the materials are lubricated during testing. The block and ring materials were an AISI 1018 steel and an AISI D2 steel, respectively (Table 1). Testing was done at room temperature $\left(25^{\circ} \mathrm{C}\right)$ under the following parameters: a normal load of $750 \mathrm{~N}$ (contact pressure of $\sim 0.5 \mathrm{GPa}), 200 \mathrm{rpm}$, and a duration of the run of $3600 \mathrm{~s}$. Five tests were performed for each nanofluid; after each test wear mass loss of blocks was recorded and COF was obtained. 


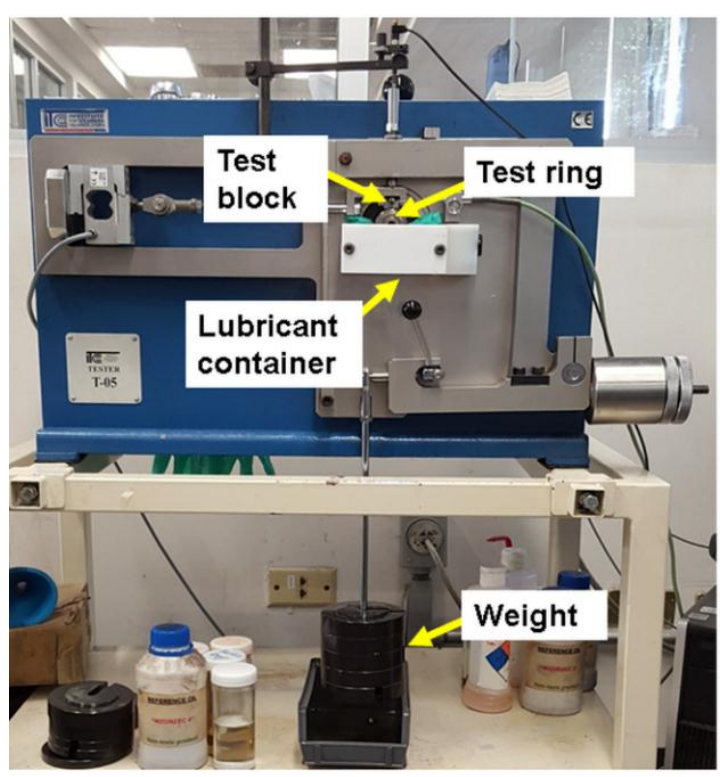

(a)

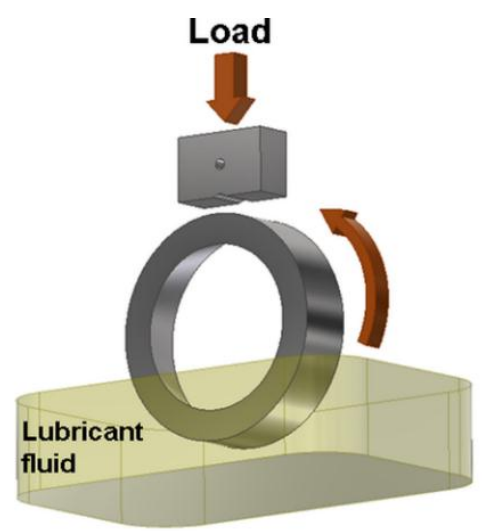

(b)
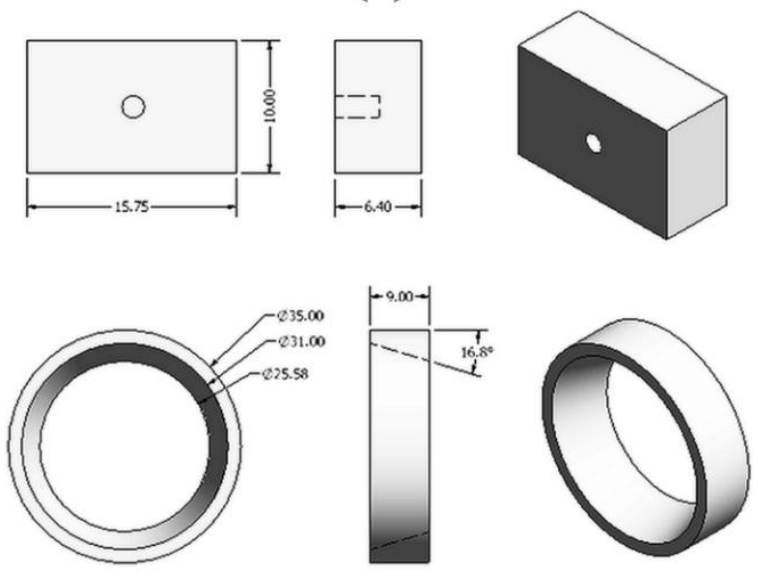

(c)

Figure 3. (a) T-05 Block-on-ring tribotester; (b) Schematic of the block-on-ring setup showing the direction of the applied force; (c) Dimensions of the test block and ring.

\subsection{Surface Characterization}

Surface roughness characteristics of average roughness $\left(R_{a}\right)$, root-mean-square roughness $\left(R_{q}\right)$, and mean roughness depth $\left(R_{z}\right)$ were characterized with an Alicona IF-EdgeMaster optical 3D surface measurement system (Alicona Imaging GmbH, Raaba/Graz, Austria). A Tescan Vega3 SB Scanning Electron Microscope (SEM) equipped with EDS (Tescan, Brno-Kohoutovice, Czech Republic) was used to identify the tribological mechanism provided by HNTs.

\section{Results and Discussion}

\subsection{Tribological Results}

Block mass loss presented in Figure 4 was quantified by weighting each block before and after every test. In general, the SF + HNT nanofluids exhibited the best tribological behavior with much lower wear mass loss compared to MO + HNT nanofluids. This was likely due to the higher viscosity of SF compared to MO $\left(75.0 \mathrm{~mm}^{2} / \mathrm{s}\right.$ vs. $\left.33.2 \mathrm{~mm}^{2} / \mathrm{s}\right)$ that was able to provide a better lubricant film and nanoparticle stability, as shown in Figure 2. For MO + HNT nanofluids the lowest wear mass loss was $8.05 \mathrm{mg}$ for $\mathrm{MO}+0.10 \mathrm{wt}$. \% HNTs, giving an enhancement of $24 \%$ compared to the unfilled MO. For SF + HNT nanofluids improvements of $6 \%, 36 \%$, and $63 \%$ were found for $0.01,0.05$, and $0.1 \mathrm{wt}$. \% HNTs, respectively. Only $2.5 \mathrm{mg}$ of mass loss was obtained for SF + $0.1 \mathrm{wt}$ \% HNTs compared to $6.9 \mathrm{mg}$ for the unfilled SF. It is also observed that the standard deviation of the wear mass results diminishes with increasing nanoparticle concentration, thus increasing nanolubricant reliability. 


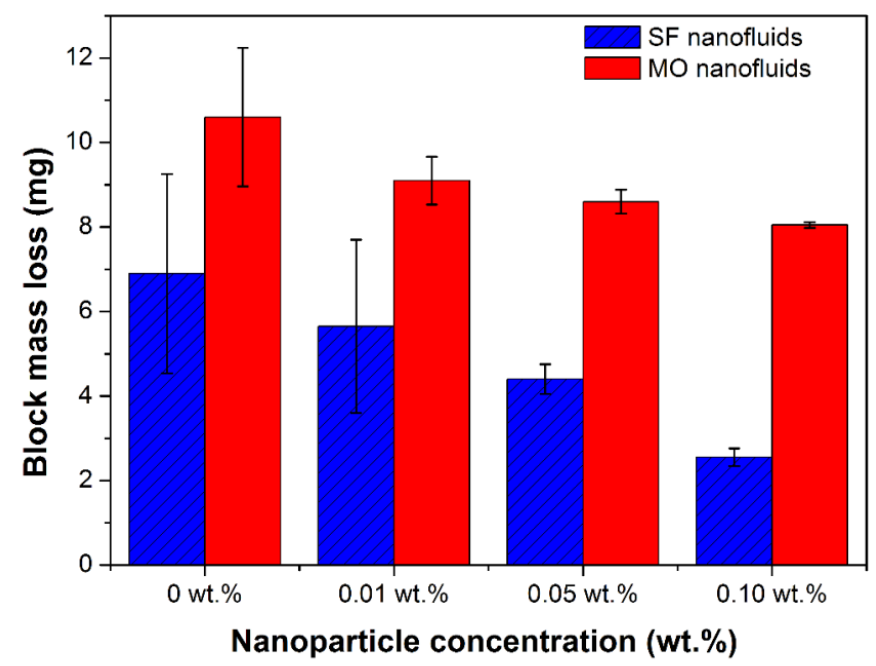

Figure 4. Block mass loss for SF and MO nanofluids with varying concentrations of HNTs.

Measurements of COF over the duration of the run are presented in Figure 5. These were calculated by taking the friction force measured through a load cell and dividing it by the applied load of 750 N. For SF nanofluids (Figure 5b) the improvements are significantly larger than the ones obtained with MO. Figure 5 a also shows that HNTs slightly decreased COF over time with $0.05 \mathrm{wt}$. \% and $0.10 \mathrm{wt}$. \% HNTs in MO due to a polishing effect provided by nanoparticles that reduced the amount of asperities and metal-metal contact. The slight variations (peaks and valleys) over time found for Figure $5 \mathrm{~b}$ may be due to the presence of wear debris that affected the measurement.

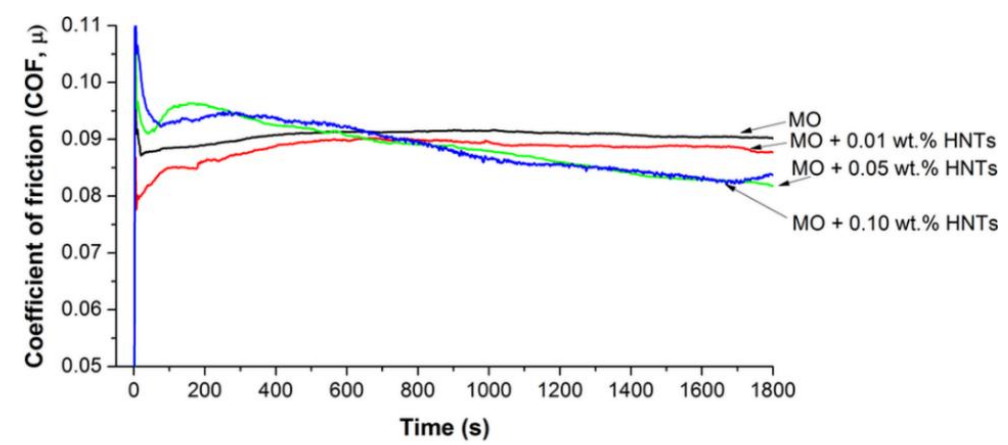

(a)

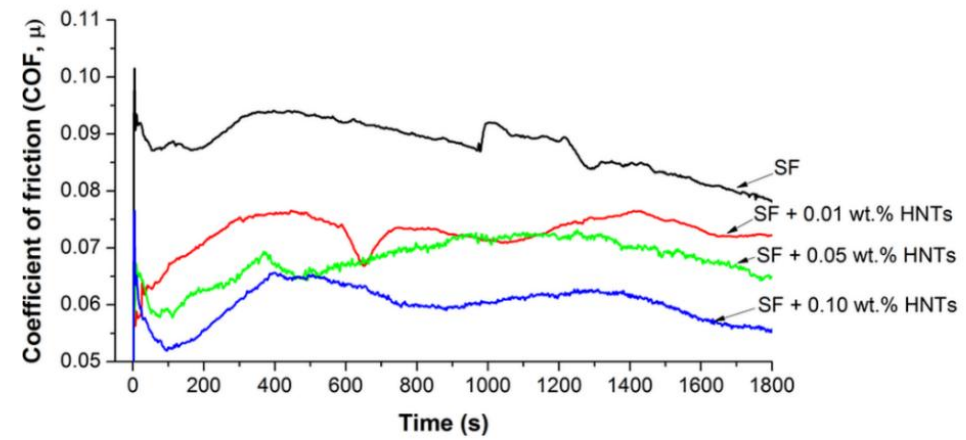

(b)

Figure 5. Coefficient of friction (COF) behavior as a function of time for: (a) MO + HNT nanofluids; (b) SF + HNT nanofluids. 
For the average COF measurements in the steady state (Figure 6) SF + HNTs nanofluids exhibited lower values compared to $\mathrm{MO}$ nanofluids, consistent with wear mass loss results. Here, it is evident that HNTs showed no major improvements in COF when added to MO. Nanofluids of SF + HNTs showed a clear tendency to reduce COF with increasing HNTs concentration. A COF of 0.088 was found for unfilled SF, whereas SF + $0.1 \mathrm{wt}$. \% HNTs exhibited a COF of 0.06 , representing a reduction of $32 \%$.

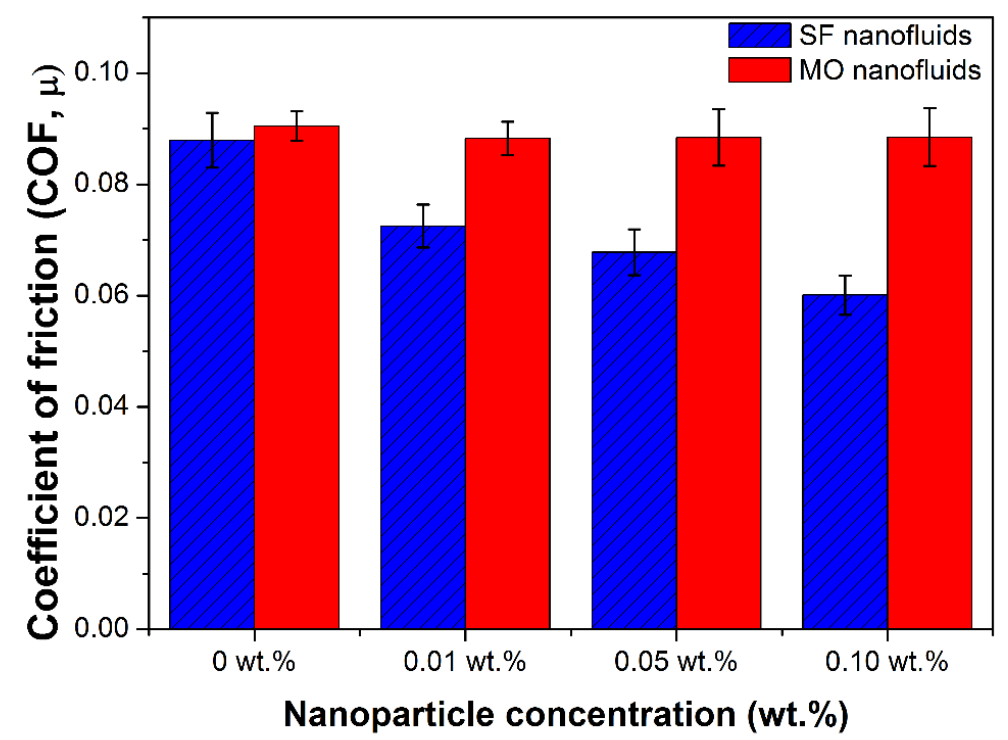

Figure 6. Coefficient of friction values for $\mathrm{MO}$ and $\mathrm{SF}$ nanofluids with varying HNT nanoparticle concentration.

\subsection{Surface Analysis}

Micrographs of worn surfaces of tested blocks with MO + HNT and SF + HNT suspensions are shown in Figures 7 and 8, respectively. The worn block in Figure 7a with MO shows pitting throughout the sample. Fewer regions with pitting are found for Figure $7 \mathrm{~b}$ with $\mathrm{MO}+0.01 \mathrm{wt}$. \% HNTs. Pitting wear is further reduced with higher nanoparticle content on the worn surfaces observed in Figure $7 \mathrm{c}, \mathrm{d}$ with 0.05 wt. \% and 0.10 wt. \% HNTs.

Figure 8 with SF nanofluids presents overall smoother surfaces compared to MO nanofluids (Figure 7). Figure 8a (unfilled SF) shows very few regions with pitting and shallow furrows. Lower groove density with increasing HNT concentration is evident in Figure 8b-d, with a very smooth surface found with $0.10 \mathrm{wt}$. \% HNTs.

Surface roughness profiles of worn blocks shown in Figures 7 and 8 taken perpendicularly to the sliding direction of the test are depicted in Figures 9 and 10, respectively. Table 2 presents surface roughness parameters of $R a, R q$, and $R z$ characterized by an optical measurement system. For both MO and $\mathrm{SF}$, the nanofluids roughness parameter values were very similar, and decreased with increasing HNT concentration. Reductions in $R_{a}$ by $36 \%$ and $34 \%$ were obtained for MO and SF nanofluids, respectively, at $0.10 \mathrm{wt}$. \% HNTs. Lower $R_{a}$ values achieved with HNTs were due to a higher amount of removed material during the wear testing that provided a polishing effect, as observed in Figures 7 and 8. Similar results have been found by Sia et al. [20] with nanoparticles effectively reducing the $R_{a}$ of surfaces through metal removal. 


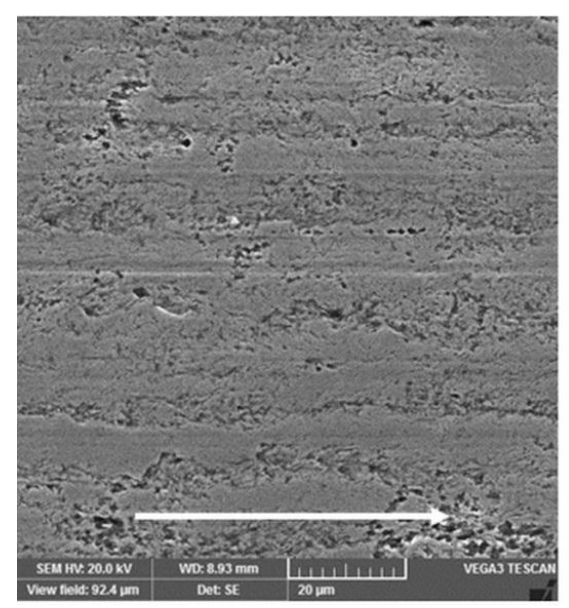

(a)

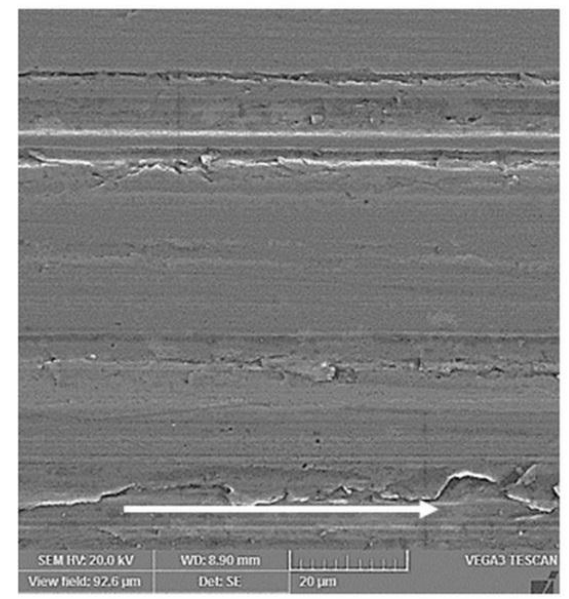

(c)

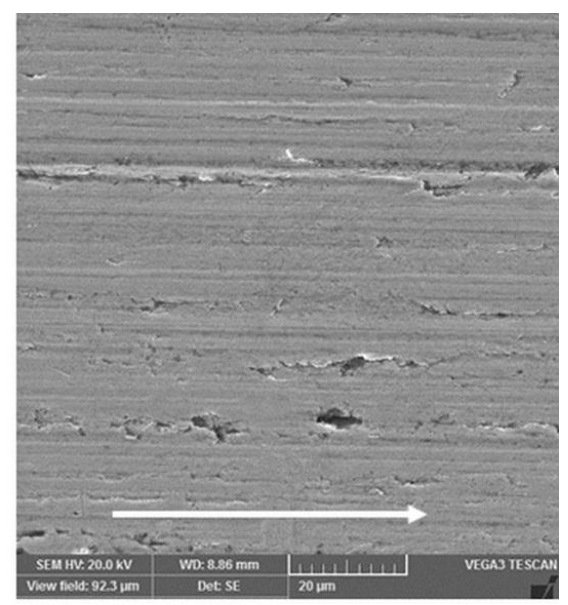

(b)

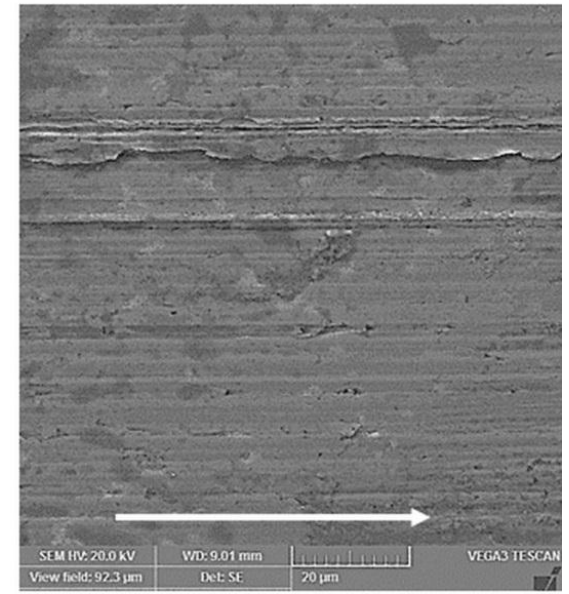

(d)

Figure 7. Scanning electron micrographs of blocks after tribological testing of: (a) $\mathrm{MO}$, (b) $\mathrm{MO}+$ 0.01 wt. \% HNTs, (c) MO + 0.05 wt. \% HNTs, (d) MO + 0.10 wt. \% HNTs. Arrows indicate the direction of sliding.

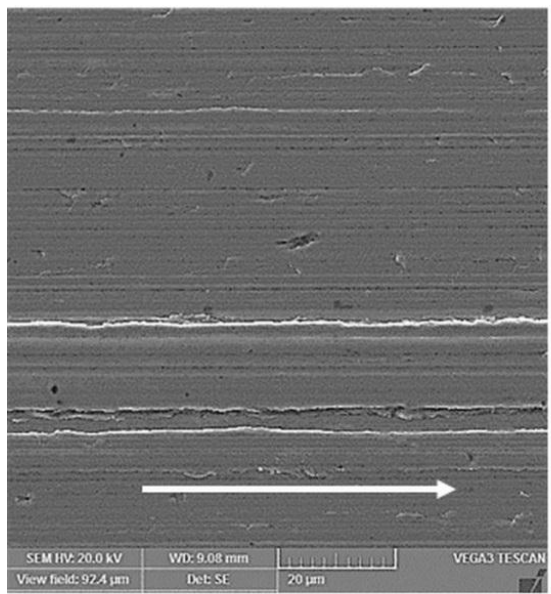

(a)

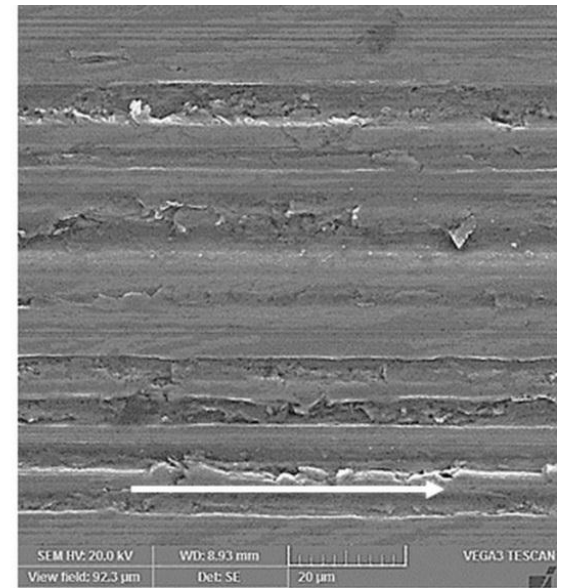

(b)

Figure 8. Cont. 


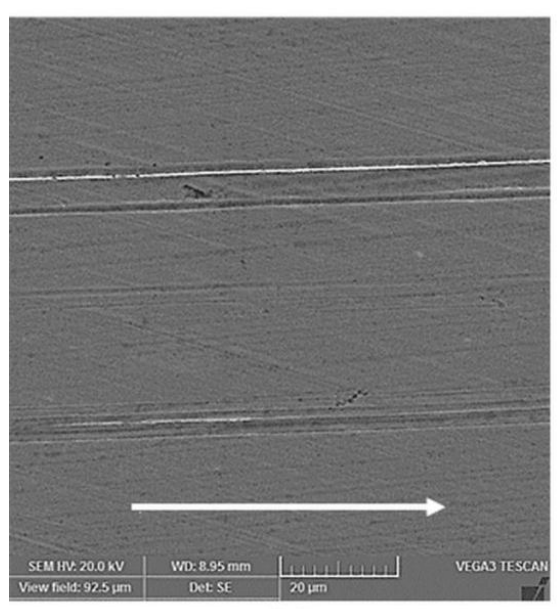

(c)

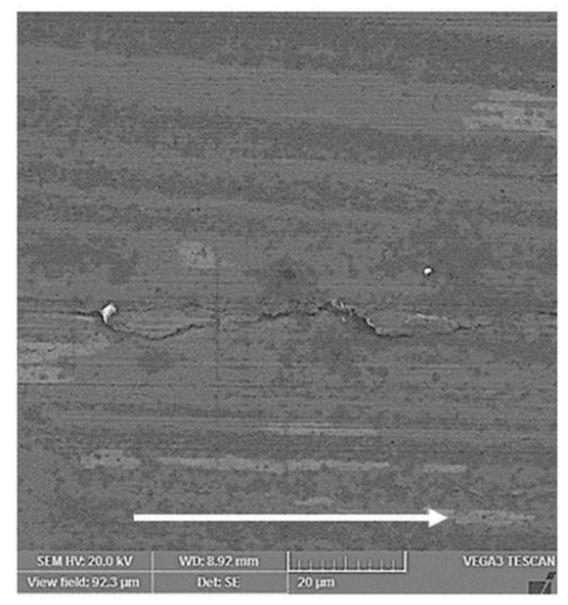

(d)

Figure 8. Scanning electron micrographs after tribological testing of: (a) SF; (b) SF +0.01 wt. \% HNTs; (c) SF +0.05 wt. \% HNTs; (d) SF + 0.10 wt. \% HNTs. Arrows indicate the direction of sliding.

Elemental analysis performed by EDS on the worn blocks tested with $\mathrm{MO}+0.10 \mathrm{wt}$ \% $\mathrm{HNTs}$ and SF +0.10 wt. \% HNTs can be observed in Figure 11a,b, respectively. No Al and/or Si elements were detected on the surface, suggesting that at the contact pressure of this test of $0.5 \mathrm{GPa}$ there was no HNT deposition and formation of a protective film. Furthermore, nanoparticles were too large to fill valleys or grooves of surfaces and provide a mending tribological mechanism.

This is in contrast to previously reported results by our group [33], where at 3.5-3.9 GPa (in a four-ball extreme pressure test) $\mathrm{Al}$ and Si groups were found on the surface, likely due to HNT exfoliation due to the compression forces. As explained by Lecouvet et al. [34], HNTs are hard aluminosilicates with interlayer water molecules where weak Van der Waals forces and H-bonds are present, and shearing occurs due to the slip motion between these layers, particularly for larger nanoparticle diameters $(>120 \mathrm{~nm})$. A similar behavior has also been reported experimentally by

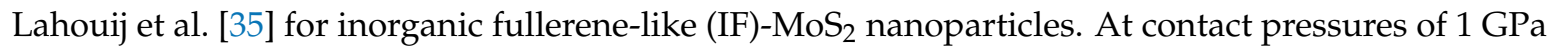
exfoliation of outer fullerene sheets was found to be the predominant mechanism, and at lower pressures $(0.1 \mathrm{GPa})$ a rolling/sliding mechanism was observed. It is explained that under compression forces the IF nanoparticles gradually deform and start to exfoliate, which is enhanced by the large number of defects in the layers.

It is then proposed that the enhancement in tribological properties provided by HNTs can be attributed to a third body mechanism, where nanoparticles separate surfaces reducing the real area of contact and reducing wear, as proposed by Ghaednia et al. [36], and their possible sliding between surfaces. The schematic of the anti-wear mechanism provided by HNTs is shown in Figure 12. As observed in Figures 4 and 5, increasing HNTs concentration resulted in lower wear mass loss due to more nanoparticles on the wear zone that were able to reduce the area of contact and decreased friction and wear. For MO nanofluids the lower stability of HNTs shown in Figure 2 likely caused more precipitation, thus fewer nanoparticles were able to separate surfaces explaining their poorer performance compared to SF nanofluids. 


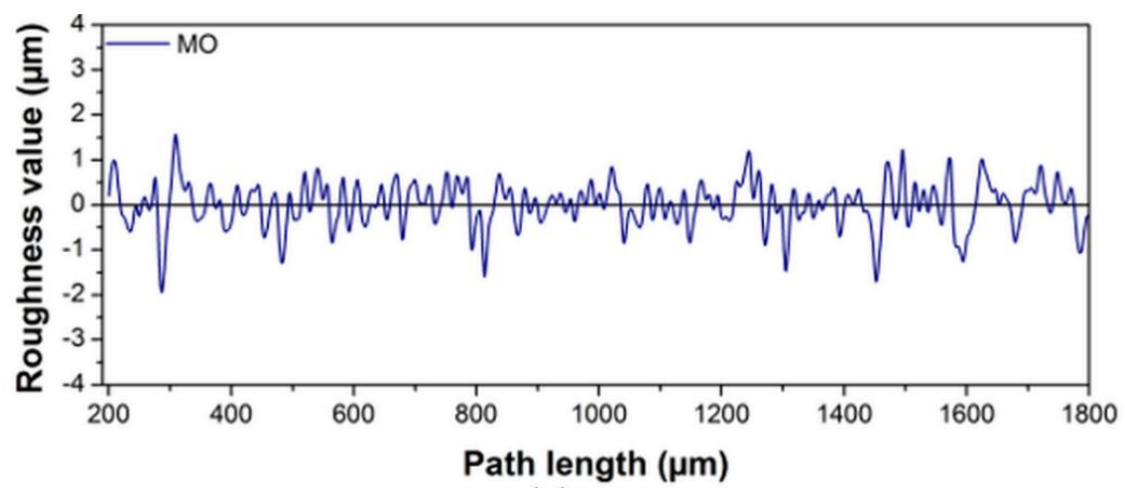

(a)

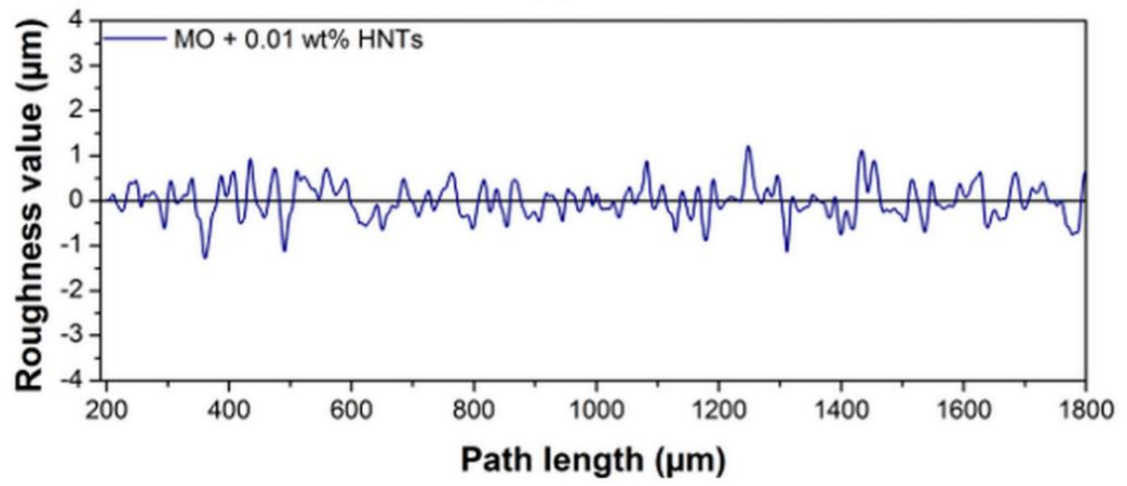

(b)

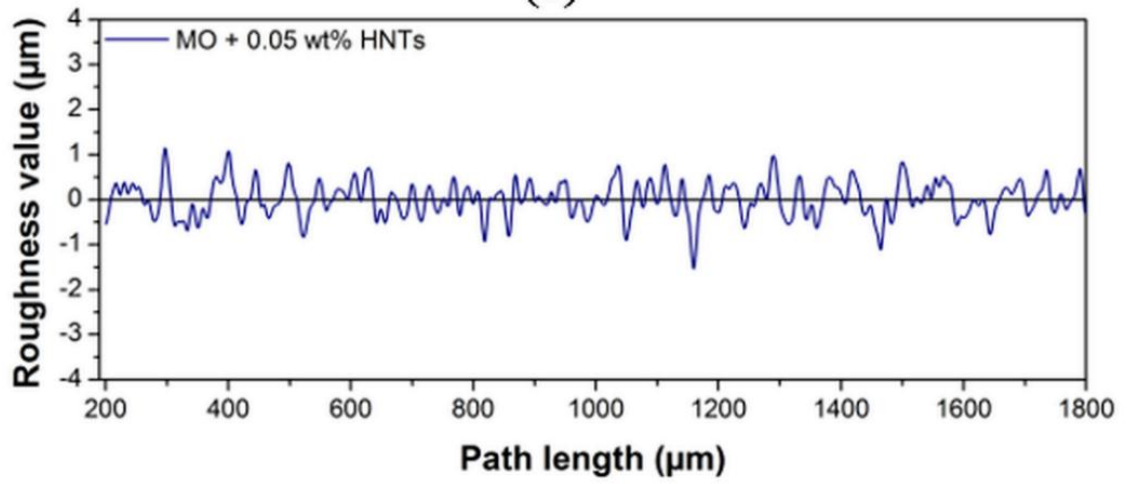

(c)

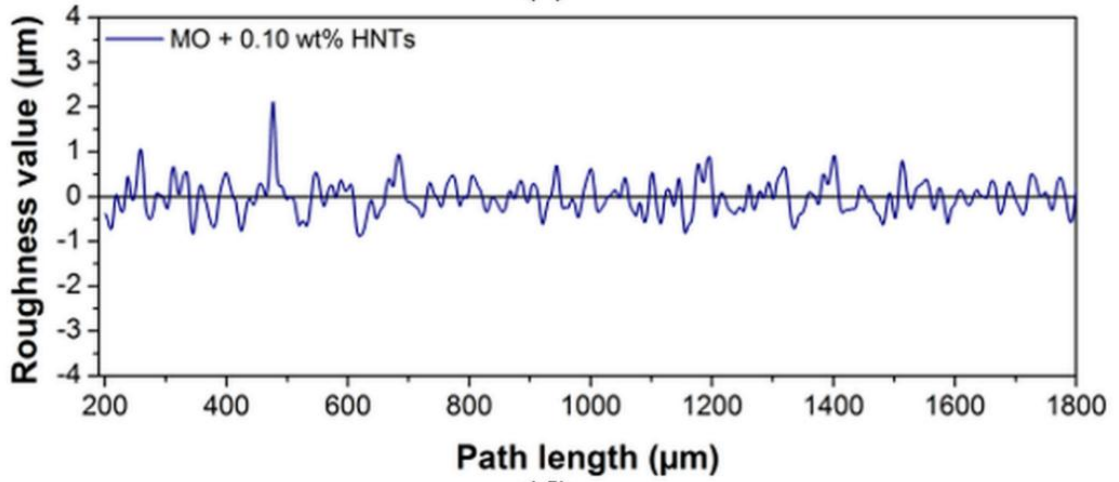

(d)

Figure 9. Roughness profiles and Ra values of worn blocks for MO + HNT nanofluidos: (a) MO, (b) $\mathrm{MO}+0.01$ wt. \% HNTs, (c) MO + 0.05 wt. \% HNTs, (d) MO + 0.10 wt. \% HNTs. 


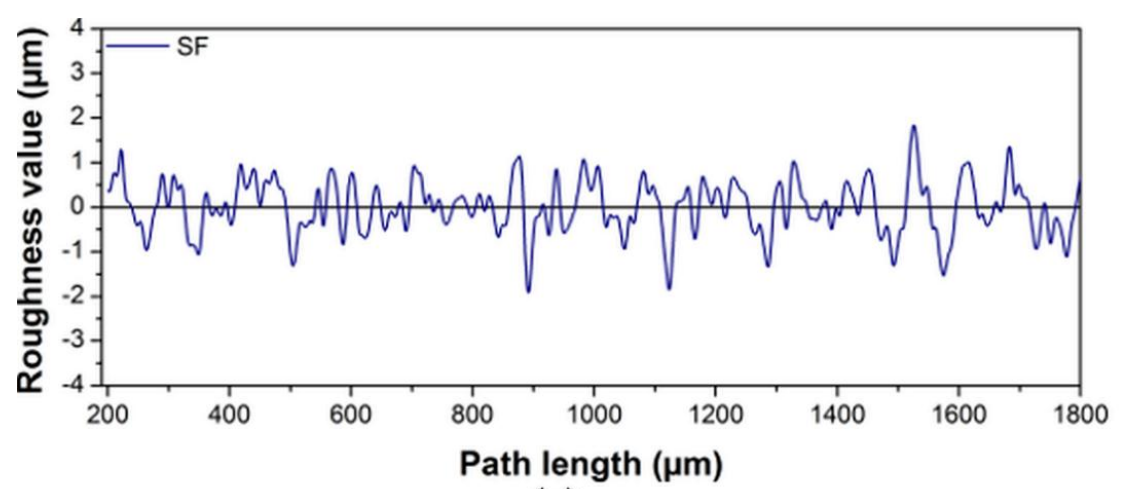

(a)

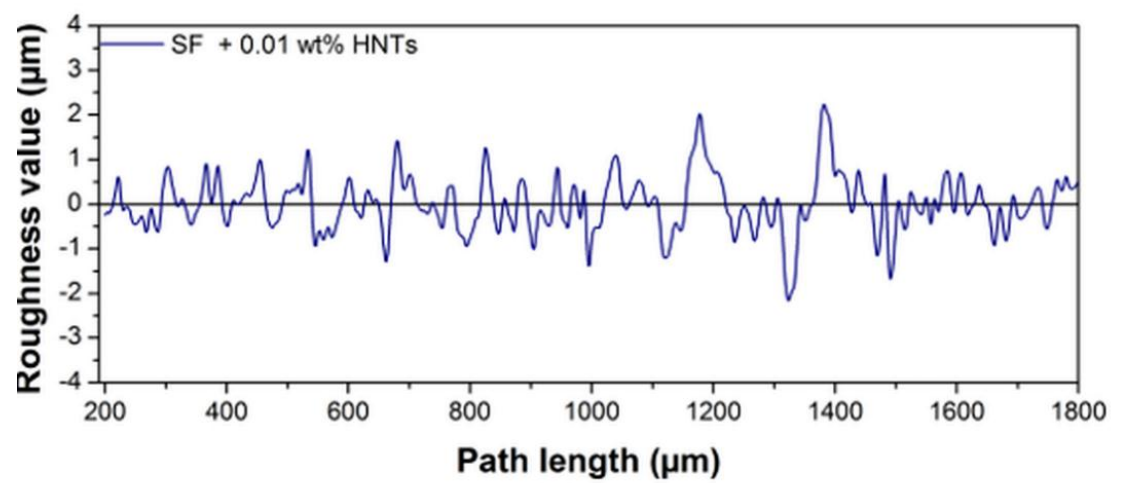

(b)

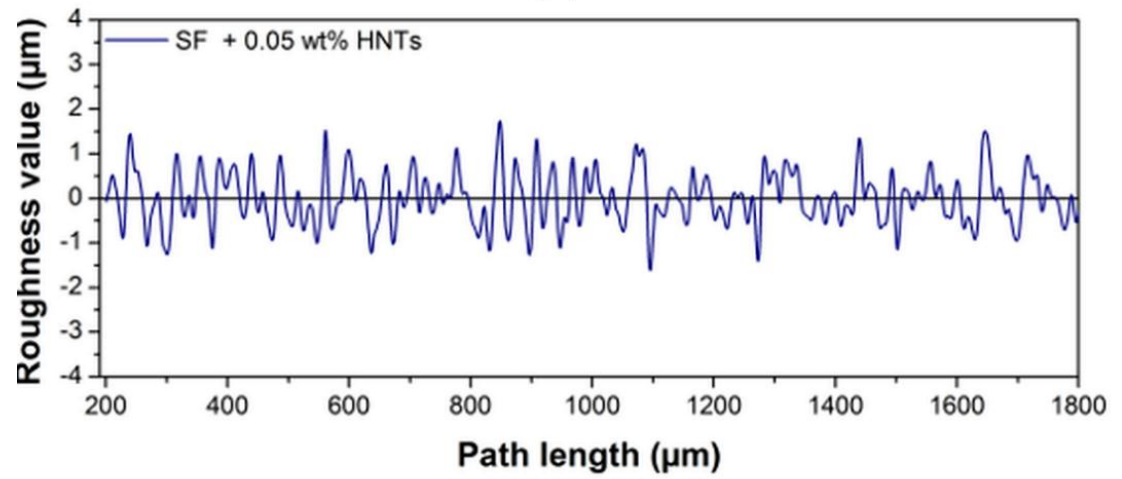

(c)

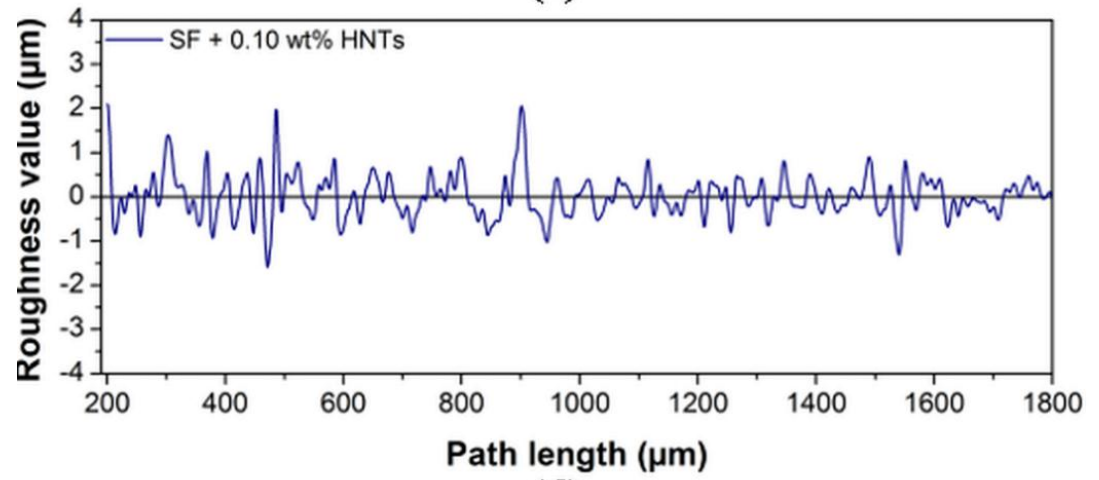

(d)

Figure 10. Roughness profiles and Ra values of worn blocks for SF + HNT nanofluidos: (a) SF; (b) SF + 0.01 wt. \% HNTs; (c) SF + 0.05 wt. \% HNTs; (d) SF + 0.10 wt. \% HNTs. Arrows indicate the direction of sliding. 
Table 2. Comparison of surface roughness characteristics of block materials.

\begin{tabular}{|c|c|c|c|}
\hline & $\begin{array}{l}\text { Average Roughness, } \\
\qquad R_{a}(\mu \mathrm{m})\end{array}$ & $\begin{array}{l}\text { Root Mean Square, } \\
\qquad R_{q}(\mu \mathrm{m})\end{array}$ & $\begin{array}{c}\text { Mean Roughness } \\
\text { Depth, } R_{z}(\mu \mathrm{m})\end{array}$ \\
\hline MO & 0.53 & 0.80 & 4.47 \\
\hline $\mathrm{MO}+0.01$ wt. $\%$ & 0.44 & 0.58 & 2.92 \\
\hline $\mathrm{MO}+0.05$ wt. $\%$ & 0.37 & 0.52 & 3.15 \\
\hline $\mathrm{MO}+0.10$ wt. $\%$ & 0.34 & 0.46 & 2.75 \\
\hline SF & 0.53 & 0.68 & 3.29 \\
\hline$S F+0.01$ wt. $\%$ & 0.47 & 0.63 & 2.83 \\
\hline SF + 0.05 wt. $\%$ & 0.42 & 0.61 & 2.94 \\
\hline$S F+0.10$ wt. $\%$ & 0.35 & 0.46 & 2.48 \\
\hline
\end{tabular}

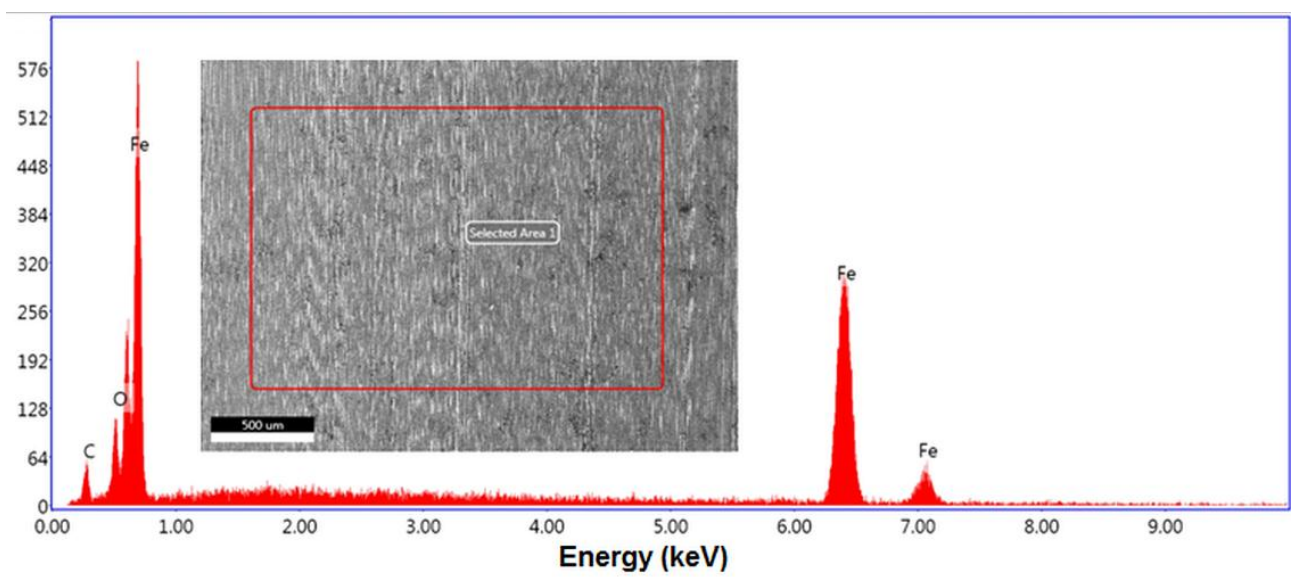

(a)

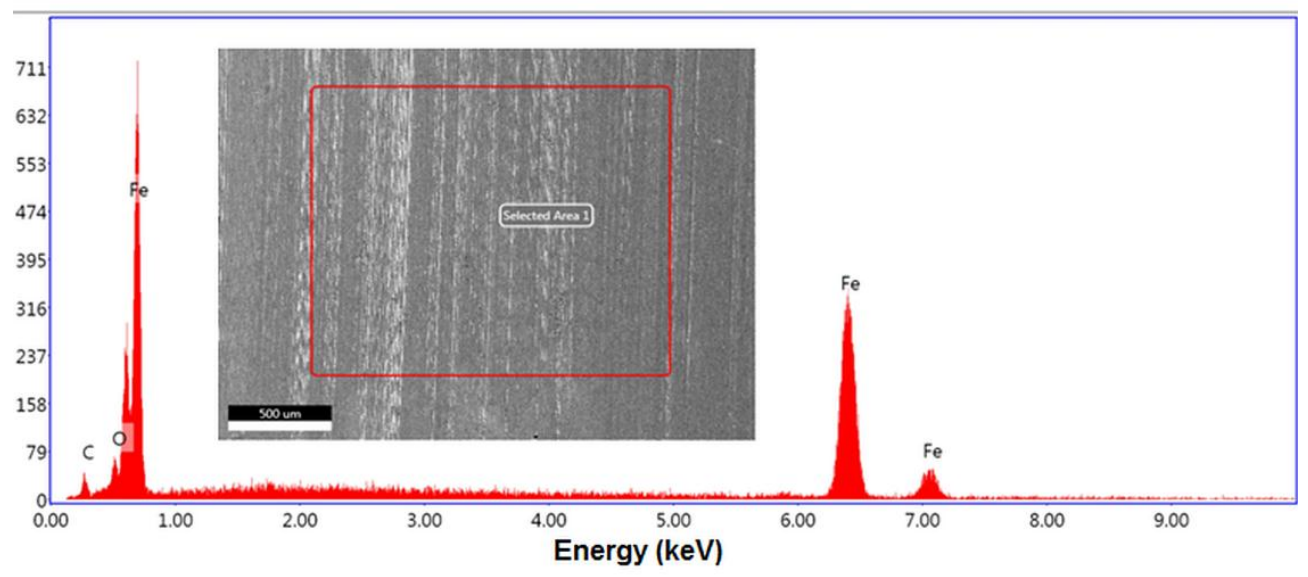

(b)

Figure 11. Elemental analysis of worn blocks after tribological testing for: (a) MO + 0.10 wt. \% HNTs, and; (b) SF + 0.10 HNTs. 


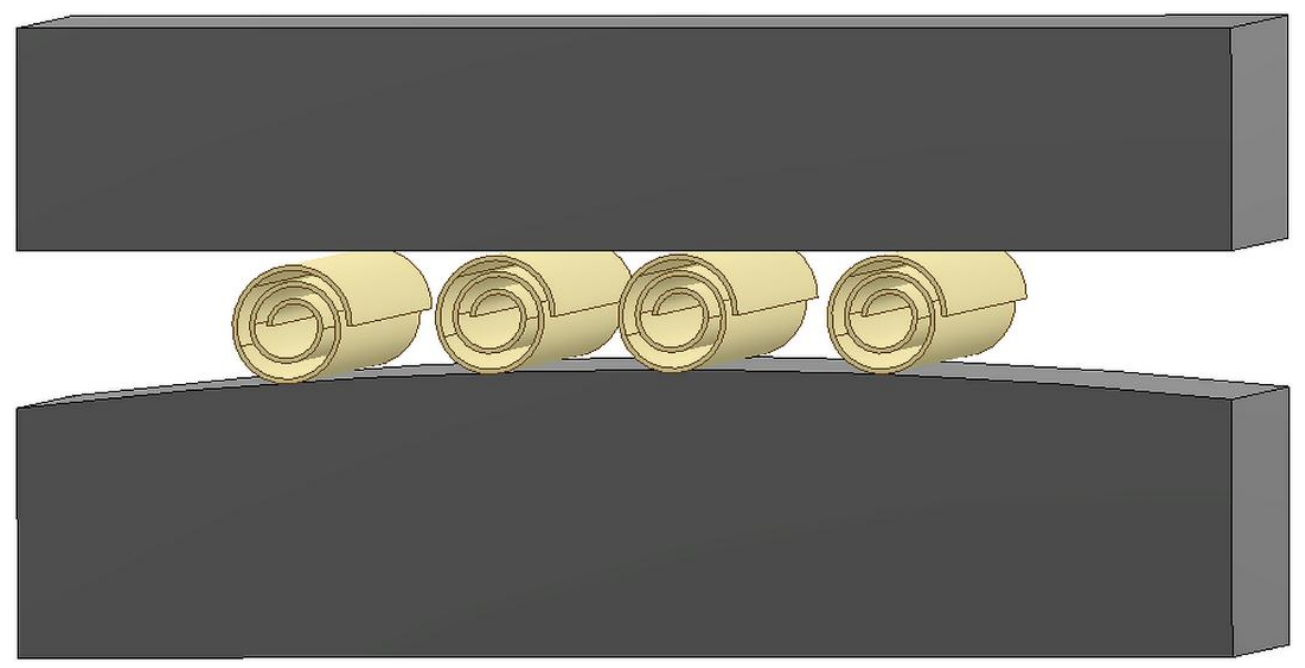

Figure 12. Schematic of anti-wear mechanism for HNTs nanofluids. A reduction of the real area of contact and sliding between surfaces with no deposition is proposed.

Overall, the significant difference in performance per concentration between the nanofluids of $\mathrm{MO}$ and SF are due to the different anti-wear characteristics of each base fluid, and physical properties such as fluid viscosity. The results shown in this study suggest that eco-friendly HNTs have a positive effect improving tribological properties of MWFs. Surface roughness and wear mass loss may be lowered due to a reduction of the contact area between surfaces by HNTs, thus extending tool life, reducing material costs, and improving the surface finish of products.

\section{Conclusions}

In this work, two MWFs filled with low concentrations of HNT additives were prepared and their anti-wear tribological properties were characterized with a T-05 block-on-ring tribotester. Nanoparticle additives effectively reduced wear mass loss for both MO and SF nanofluids, with improvements of up to $64 \%$. Surface roughness of blocks and COF were also lowered. At the contact pressure of the test of $0.5 \mathrm{GPa}$ HNTs showed no exfoliation, thus the enhancement in anti-wear properties is attributed to a reduction of contact area.

Acknowledgments: This works was partially supported by Vicerrectoría Académica Universidad de Monterrey research grant No. 15013. The authors would like to acknowledge Manuel Morales for his contribution to this work.

Author Contributions: L.P.-P. conceived and designed the experiments and wrote the paper; J.A.S.-F. contributed materials, performed EDS experiments, and analyzed the data; C.R.M., J.A.O., K.I.S., L.M.U., M.J.A., and P.G.-P. performed tribological and surface roughness characterization experiments and analyzed the data; B.C. performed SEM and surface roughness characterization and analyzed the data.

Conflicts of Interest: The authors declare no conflict of interest.

\section{References}

1. Brinksmeier, E.; Meyer, D.; Huesmann-Cordes, A.G.; Herrmann, C. Metalworking fluids-Mechanisms and performance. CIRP Ann. 2015. [CrossRef]

2. Schwarz, M.; Dado, M.; Hnilica, R.; Veverkoná, D. Environmental and health aspects of metalworking fluid use. Polish J. Environ. Stud. 2015, 24, 37-45.

3. Do, T.-V.; Hsu, Q.-C. Optimization of Minimum Quantity Lubricant Conditions and Cutting Parameters in Hard Milling of AISI H13 Steel. Appl. Sci. 2016, 6, 83. [CrossRef]

4. Gariani, S.; Shyha, I.; Inam, F.; Huo, D. Evaluation of a Novel Controlled Cutting Fluid Impinging Supply System When Machining Titanium Alloys. Appl. Sci. 2017, 7, 560. [CrossRef] 
5. Wu, Y.Y.; Tsui, W.C.; Liu, T.C. Experimental analysis of tribological properties of lubricating oils with nanoparticle additives. Wear 2007, 262, 819-825. [CrossRef]

6. Gara, L.; Zou, Q. Friction and Wear Characteristics of Water-Based $\mathrm{ZnO}$ and $\mathrm{Al}_{2} \mathrm{O}_{3}$ Nanofluids. Tribol. Trans. 2012, 55, 345-350. [CrossRef]

7. Wong, K.V.; De Leon, O. Applications of nanofluids: Current and future. Adv. Mech. Eng. 2010, 2010. [CrossRef]

8. Yu, W.; Xie, H. A review on nanofluids: Preparation, stability mechanisms, and applications. J. Nanomater. 2012, 2012. [CrossRef]

9. Thottackkad, M.V.; Rajendrakumar, P.K.; Prabhakaran Nair, K.P. Experimental studies on the tribological behaviour of engine oil (SAE15W40) with the addition of $\mathrm{CuO}$ nanoparticles. Ind. Lubr. Tribol. 2014, 66, 289-297. [CrossRef]

10. Peña-Parás, L.; Taha-Tijerina, J.; García, A.; Maldonado, D.; González, J.A.; Molina, D.; Palacios, E.; Cantú, P. Antiwear and Extreme Pressure Properties of Nanofluids for Industrial Applications. Tribol. Trans. 2014, 57, 1072-1076. [CrossRef]

11. Vázquez, K.D.; Cantú, D.S.; Segura, A.F.; Araiz, F.; Peña-Parás, L.; Maldonado, D. Application of Nanofluids to improve tool life in machining processes. In Proceedings of the LUBMAT 2014, Manchester, UK, 25-27 June 2014; pp. 1-8.

12. Mosleh, M.; Ghaderi, M. Deagglomeration of Transfer Film in Metal Contacts Using Nanolubricants. Tribol. Trans. 2012, 55, 52-58. [CrossRef]

13. Ge, X.; Xia, Y.; Shu, Z.; Zhao, X. Conductive grease synthesized using nanometer ATO as an additive. Friction 2015, 3, 56-64. [CrossRef]

14. Le, V.; Lin, J.-W. Tribological Properties of Aluminum Nanoparticles as Additives in an Aqueous Glycerol Solution. Appl. Sci. 2017, 7, 80. [CrossRef]

15. Mosleh, M.; Atnafu, N.D.; Belk, J.H.; Nobles, O.M. Modification of sheet metal forming fluids with dispersed nanoparticles for improved lubrication. Wear 2009, 267, 1220-1225. [CrossRef]

16. Zhang, M.; Wang, X.; Fu, X.; Xia, Y. Performance and anti-wear mechanism of $\mathrm{CaCO}_{3}$ nanoparticles as a green additive in poly-alpha-olefin. Tribol. Int. 2009, 42, 1029-1039. [CrossRef]

17. Kalin, M.; Kogovšek, J.; Remškar, M. Nanoparticles as novel lubricating additives in a green, physically based lubrication technology for DLC coatings. Wear 2013, 303, 480-485. [CrossRef]

18. Park, K.-H.; Ewald, B.; Kwon, P.Y. Effect of Nano-Enhanced Lubricant in Minimum Quantity Lubrication Balling Milling. J. Tribol. 2011, 133, 31803. [CrossRef]

19. Sia, S.Y.; Sarhan, A.A.D. Morphology investigation of worn bearing surfaces using $\mathrm{SiO}_{2}$ nanolubrication system. Int. J. Adv. Manuf. Technol. 2014, 70, 1063-1071. [CrossRef]

20. Sia, S.Y.; Bassyony, E.Z.; Sarhan, A.A.D. Development of SiO2 nanolubrication system to be used in sliding bearings. Int. J. Adv. Manuf. Technol. 2014, 71, 1277-1284. [CrossRef]

21. Rahmati, B.; Sarhan, A.A.D.; Sayuti, M. Morphology of surface generated by end milling AL6061-T6 using molybdenum disulfide $\left(\mathrm{MoS}_{2}\right)$ nanolubrication in end milling machining. J. Clean. Prod. 2014, 66, 685-691. [CrossRef]

22. Liu, M.; Jia, Z.; Jia, D.; Zhou, C. Recent advance in research on halloysite nanotubes-polymer nanocomposite. Prog. Polym. Sci. 2014, 39, 1498-1525. [CrossRef]

23. Rawtani, D.; Agrawal, Y.K. Multifarious applications of halloysite nano tubes: A review. Rev. Adv. Mater. Sci. 2012, 30, 282-295.

24. Pasbakhsh, P.; Churchman, G.J.; Keeling, J.L. Characterisation of properties of various halloysites relevant to their use as nanotubes and microfibre fillers. Appl. Clay Sci. 2013, 74, 47-57. [CrossRef]

25. Makaremi, M.; Pasbakhsh, P.; Cavallaro, G.; Lazzara, G.; Aw, Y.K.; Lee, S.M.; Milioto, S. Effect of Morphology and Size of Halloysite Nanotubes on Functional Pectin Bionanocomposites for Food Packaging Applications. ACS Appl. Mater. Interfaces 2017, 9, 17476-17488. [CrossRef] [PubMed]

26. Sánchez-Fernández, A.; Peña-Parás, L.; Vidaltamayo, R.; Cué-Sampedro, R.; Mendoza-Martínez, A.; Zomosa-Signoret, V.; Rivas-Estilla, A.; Riojas, P. Synthesization, Characterization, and in Vitro Evaluation of Cytotoxicity of Biomaterials Based on Halloysite Nanotubes. Materials 2014, 7, 7770-7780. [CrossRef] [PubMed]

27. Lvov, Y.; Abdullayev, E. Functional polymer-Clay nanotube composites with sustained release of chemical agents. Prog. Polym. Sci. 2013, 38, 1690-1719. [CrossRef] 
28. Massaro, M.; Lazzara, G.; Milioto, S.; Noto, R.; Riela, S. Covalently modified halloysite clay nanotubes: Synthesis, properties, biological and medical applications. J. Mater. Chem. B 2017, 5, 4246. [CrossRef]

29. Bertolino, V.; Cavallaro, G.; Lazzara, G.; Milioto, S.; Parisi, F. Biopolymer-Targeted Adsorption onto Halloysite Nanotubes in Aqueous Media. Langmuir 2017, 33, 3317-3323. [CrossRef] [PubMed]

30. Cavallaro, G.; Danilushkina, A.; Evtugyn, V.; Lazzara, G.; Milioto, S.; Parisi, F.; Rozhina, E.; Fakhrullin, R. Halloysite Nanotubes: Controlled Access and Release by Smart Gates. Nanomaterials 2017, 7, 199. [CrossRef] [PubMed]

31. Cavallaro, G.; Lazzara, G.; Milioto, S.; Parisi, F. Hydrophobically Modified Halloysite Nanotubes as Reverse Micelles for Water-in-Oil Emulsion. Langmuir 2015, 31, 7472-7478. [CrossRef] [PubMed]

32. Cavallaro, G.; Lazzara, G.; Milioto, S.; Parisi, F.; Sanzillo, V. Modified halloysite nanotubes: Nanoarchitectures for enhancing the capture of oils from vapor and liquid phases. ACS Appl. Mater. Interfaces 2014, 6, 606-612. [CrossRef] [PubMed]

33. Peña-Parás, L.; Maldonado-Cortés, D.; García, P.; Irigoyen, M.; Taha-Tijerina, J.; Guerra, J. Tribological performance of halloysite clay nanotubes as green lubricant additives. Wear 2017, 376-377, 885-892. [CrossRef]

34. Lecouvet, B.; Horion, J.; D’haese, C.; Bailly, C.; Nysten, B.; D’Haese, C.; Bailly, C.; Nysten, B. Elastic modulus of halloysite nanotubes. Nanotechnology 2013, 24, 105704. [CrossRef] [PubMed]

35. Lahouij, I.; Dassenoy, F.; Vacher, B.; Martin, J.-M. Real Time TEM Imaging of Compression and Shear of Single Fullerene-Like MoS2 Nanoparticle. Tribol. Lett. 2012, 45, 131-141. [CrossRef]

36. Ghaednia, H.; Jackson, R.L. The Effect of Nanoparticles on the Real Area of Contact, Friction, and Wear. J. Tribol. 2013, 135, 41603. [CrossRef]

(C) 2017 by the authors. Licensee MDPI, Basel, Switzerland. This article is an open access article distributed under the terms and conditions of the Creative Commons Attribution (CC BY) license (http:/ / creativecommons.org/licenses/by/4.0/). 